\title{
Development and Validation of a Stability Indicating HPLC Method for the Simultaneous Analysis of Esomeprazole and Itopride in Bulk and In Capsules
}

\author{
M. Nageswara Rao, K. B. M. Krishna, B. Hari Babu* \\ Department of Chemistry, Acharya Nagarjuna University, Nagarjuna nagar, Guntur, India.
}

\section{ARTICLE INFO}

Article history:

Received on: $17 / 11 / 2015$

Revised on: 04/12/2015

Accepted on: 23/12/2015

Available online: 27/02/2016

Key words:

Esomeprazole, Itopride, stability indicating, HPLC, capsules.

\begin{abstract}
A rapid, simple, selective, precise, and accurate stability indicating HPLC method has been developed and validated for the simultaneous analysis of esomeprazole and itopride in bulk and in capsule form. An isocratic separation was achieved using a Hypersil C4 $(250 \mathrm{x} 4.6 \mathrm{~mm}), 5 \mu \mathrm{m}$ particle size column with a flow rate of 1 $\mathrm{mL} / \mathrm{min}$ and photodiode array detector at $272 \mathrm{~nm}$. The mobile phase consisted of $0.1 \mathrm{M}$ dipotassium hydrogen phosphate: acetonitrile $(40: 60 \mathrm{v} / \mathrm{v})$. The method was validated for selectivity, specificity, linearity, precision, accuracy and robustness. The selectivity of the method was determined by assessing interference from the placebo, components of mobile phase and common excipients in pharmaceutical formulations. Whereas, specificity was established by stress degradation studies. The method was linear over the concentration range $40-$ $120 \mu \mathrm{g} / \mathrm{mL}\left(R^{2}=0.9999\right)$ and $150-450 \mu \mathrm{g} / \mathrm{mL}\left(R^{2}=0.9999\right)$ for esomeprazole and itopride, respectively. Limit of detection is 0.207 and $0.724 \mu \mathrm{g} / \mathrm{mL} \&$ Limit of quantitation is 0.691 and $2.415 \mu \mathrm{g} / \mathrm{mL}$ for esomeprazole and itopride, respectively. The precision and accuracy of the method was found to be acceptable. The method was found to be robust and suitable for the simultaneous analysis of esomeprazole and itopride in a capsule formulation. Degradation products resulting from the stress studies did not interfere with the detection and quantification of esomeprazole and itopride. The proposed HPLC method is thus stability-indicating.
\end{abstract}

\section{INTRODUCTION}

Esomeprazole (Evangelos and Einar, 2007; McKeage et al., 2008), chemically known as (S)-5-Methoxy-2-[(4-methoxy3,5-dimethylpyridin-2-yl)methylsulfinyl]-3H-benzoimidazole (Fig. 1), is a proton pump inhibitor. By inhibiting the $\mathrm{H}^{+} / \mathrm{K}^{+}$ ATPase in the parietal cells of the stomach, esomeprazole decreases the production of acid in the stomach. Esomeprazole is approved for the management of reflux oesophagitis, the symptomatic treatment of gastro-oesophageal reflux disease, the prevention and healing of non steroidal anti-inflammatory drugsassociated gastric ulcer disease, the treatment of duodenal ulcer disease caused by Helicobacter pylori infection and ZollingerEllison syndrome. Literature survey reveals that visible spectrophotometry (Akheel and Ayesha, 2007; Nafisur et al., 2008; Patil et al., 2009; Soujanya et al., 2014), ultra violet spectrophotometry (Putta et al., 2010; Magesh et al., 2010), HPLC (Shetty et al., 2005; ÖNal and ÖZtunÇ, 2006; Bellah et al., 2012; Khalil et al 2012; Mahaparale and Deshpande, 2015),

* Corresponding Author

Email: drharibabuanu2015@gmail.com
UPLC (Nalwade et al., 2012) and liquid chromatography with tandem mass spectrometry (Hultman et al., 2007; Sathiyaraj et al., 2010; Ramakotaiah et al., 2011) techniques have been reported for determination of esomeprazole in bulk, pharmaceutical dosage forms and biological samples.

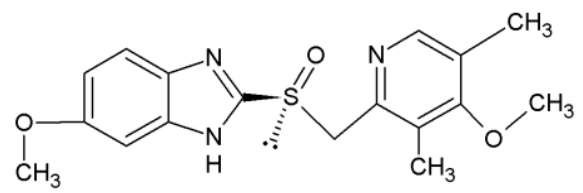

Fig. 1: Chemical structure of esomeprazole.

Itopride (Sun et al., 2011; Huang et al., 2012), chemically known as $N$-((4-(2-Dimethyl amino ethoxy) phenyl) methyl)-3,4dimethoxybenzamide (Fig. 2), is an effective anti-nauseant and promotility drug. Itopride performs action by increasing acetylcholine at nerve junctions by inhibiting acetylcholine esterase. The increased acetylcholine in turn stimulates gastric motility. Itopride is used in the treatment of dyspepsia of a nonulcer or dysmotility type, delayed gastric emptying, heartburn, anorexia, bloating, nausea and vomiting. 
Several techniques were found in the literature for the assay of itopride in bulk, pharmaceutical dosage forms and biological samples. They include visible spectrophotometry (Hussainy et al., 2006; Felice and Saradhi, 2008; Choudhary et al., 2009a; Choudhary et al., 2009b; Sneha et al., 2015), ultraviolet spectrophotometry (Santosh et al., 2010; Gupta et al., 2010), spectrofluorimetry (Mohamed et al., 2013), atomic emission spectrometry (Khalil, 2013), HPLC (Kaul et al., 2005; Neeraj et al., 2005; Singh et al., 2005; Zhao, 2000; Thiruvengada et al., 2010; Payal et al., 2011), liquid chromatography with flourometric detection (Singh et al., 2005; Pavel et al., 2009; Ma et al., 2009), HPTLC (Suganthi et al., 2006; Vidya et al., 2006; Dighe, 2007) and liquid chromatography with tandem mass spectrometry (Heon et al., 2007; Payal et al., 2011).

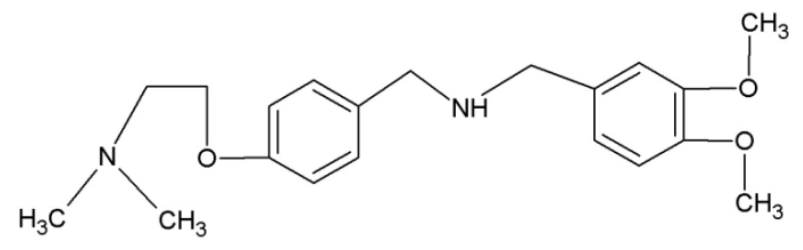

Fig. 2: Chemical structure of itopride.

Combination of esomeprazole and itopride is used for the treatment of gastric esophagus reflux disease (Peng and Li, 2009; Wang and Chen, 2012). The detailed survey of literature indicated that only two HPLC methods (Rajesh et al., 2010; Kumar et al., 2014) have been reported for the simultaneous estimation of esomeprazole and itopride in their combined dosage form. Rajesh et al., (2010) have reported an HPLC method using a Phenomenex C18 column with a mobile phase consisting of ammonium acetate buffer $(\mathrm{pH}-5.5)$, water and methanol $(25: 15: 60 \mathrm{v} / \mathrm{v})$ at a flow rate of $1.5 \mathrm{~mL} / \mathrm{min}$. In the second HPLC method reported by Kumar et $a l$. , (2014) the separation and assay of esomeprazole and itopride was carried out on Agilent Zorebax C18 column using a mixture of dipotassium hydrogen phosphate buffer $(\mathrm{pH} 7.29)$ and methanol $(60: 40, v / v)$ as mobile phase at a flow rate of $1.0 \mathrm{~mL} / \mathrm{min}$.

HPLC method reported by Rajesh et al., (2010) for simultaneous estimation of esomeprazole and itopride in pharmaceutical dosage forms were found to have drawbacks such as narrow range of linearity, less accurate and have less correlation coefficient value. Use of more flow rate $(1.5 \mathrm{~mL} / \mathrm{min})$ and triple solvent system increases the utilization of solvents, which inturn increases the cost of the analysis. Further more the method is not stability indicating. Though the Kumar et al., (2014) method is stability indicating, accurate and precise but is less sensitive. The total run time is more (>6 min) in both the reported methods. Due to lengthy total run time, the time taken for the analysis of a single sample and utilization of solvent increases.

For this reason, in the present study an attempt was made to develop an economic and rapid stability indicating reversephase high performance liquid chromatographic method for the assay of esomeprazole and itopride, simultaneously, in capsule dosage form with short run time and low solvent consumption.
The developed method was validated as per guidelines given by International Conference on Harmonization (International Conference on Harmonization, 2005).

\section{MATERIALS AND METHODS}

\section{Mobile phase}

The solvents and chemicals used in the preparation of mobile phase were of HPLC grade and analytical grade, respectively. The mobile phase used was $0.1 \mathrm{M} \mathrm{K}_{2} \mathrm{HPO}_{4}$ and acetonitrile (Merck India Ltd., Mumbai) in the ratio of 40:60 v/v. To prepare $0.1 \mathrm{M} \mathrm{K}_{2} \mathrm{HPO}_{4}, 1.75 \mathrm{~g}$ of $\mathrm{K}_{2} \mathrm{HPO}_{4}$ (Sd. Fine Chemicals Ltd., Mumbai) was dissolved in $30 \mathrm{ml}$ of double distilled water in a volumetric flask and made up to $100 \mathrm{ml}$ with double distilled water. The $\mathrm{pH}$ of the mobile phase was adjusted to 5.4 with dilute orthophoshoric acid. Before use, the mobile phase was filtered through millipore membrane filter and degassed for $15 \mathrm{~min}$ by sonication.

\section{Apparatus and chromatographic conditions}

In the present study Waters 2695 alliance with binary HPLC pump equipped with Waters 2998 PDA detector and Waters Empower2 software was used. Hypersil C4 (250 x $4.6 \mathrm{~mm} ; 5 \mu \mathrm{m}$ particle size) analytical column was used for separation and simultaneous analysis of esomeprazole and itopride. The column temperature was maintained at $30 \pm 1{ }^{\circ} \mathrm{C}$. The separation was carried out under isocratic elution. The flow rate was maintained as $1.0 \mathrm{~mL} / \mathrm{min}$. The injection volume was $10 \mu \mathrm{L}$. The eluents were detected at $272 \mathrm{~nm}$.

\section{Standard solutions}

Esomeprazole and itopride bulk samples were obtained from Lara drugs pvt Ltd., Hyderabad. The standard stock solution was prepared by dissolving $40 \mathrm{mg}$ of esomeprazole and $150 \mathrm{mg}$ of itopride in $100 \mathrm{~mL}$ mobile phase. Working standard solutions equivalent to $40,60,80,100 \& 120 \mu \mathrm{g} / \mathrm{mL}$ esomeprazole and 150 , $225,300,375 \& 450 \mu \mathrm{g} / \mathrm{mL}$ itopride was prepared from stock solution by appropriately diluting the stock standard solution with the mobile phase.

\section{Sample Solution}

Sompraz IT (Torrent Labs (P) Ltd. Ahmedabad) capsules, labeled to contain esomeprazole $40 \mathrm{mg}$ and itopride 150 $\mathrm{mg}$, were purchased and used in the present study. Ten capsules were emptied and the powder was mixed well to obtain a homogenous mixture. The powder equivalent of $40 \mathrm{mg}$ of esomeprazole and $150 \mathrm{mg}$ of itopride was transferred to a $100 \mathrm{~mL}$ volumetric flask containing $20 \mathrm{~mL}$ of mobile phase, sonicated for 20 min and made up to mark with the same solvent. The resultant mixture was filtered through $0.45 \mu \mathrm{m}$ filter. The filtrate was diluted appropriately with the mobile phase to get a final concentration $80 \mu \mathrm{g} / \mathrm{mL}$ and $300 \mu \mathrm{g} / \mathrm{mL}$ of esomeprazole and itopride, respectively. 


\section{Placebo solution}

The placebo solution was prepared by dissolving $129 \mathrm{mg}$ of placebo in $20 \mathrm{~mL}$ of mobile phase in a $100 \mathrm{~mL}$ volumetric flask. The contents of the flask was sonicated for 20 min and made up to mark with the same solvent. The resultant mixture was filtered through $0.45 \mu \mathrm{m}$ filter. Five $\mathrm{mL}$ of the above solution was diluted to $25 \mathrm{~mL}$ with mobile phase in a $25 \mathrm{~mL}$ volumetric flask.

\section{Stress degradation study}

Stress degradation study was carried out by subjecting the capsule powder to degradations such as acid, alkaline, oxidative, thermal and photolytic conditions to assess the interference of degradants.

For acidic hydrolysis, powder equivalent of $40 \mathrm{mg}$ of esomeprazole and $150 \mathrm{mg}$ of itopride was mixed with $10 \mathrm{~mL}$ of $0.1 \mathrm{~N} \mathrm{HCl}$ in $100 \mathrm{~mL}$ volumetric flask. The resultant solution was sonicated for $30 \mathrm{~min}$. After hydrolysis, the solution was neutralized with sufficient volume of $0.1 \mathrm{~N} \mathrm{NaOH}$ and diluted with mobile phase up to the mark.

For alkaline hydrolysis, powder equivalent of $40 \mathrm{mg}$ of esomeprazole and $150 \mathrm{mg}$ of itopride was mixed with $10 \mathrm{~mL}$ of $0.1 \mathrm{~N} \mathrm{NaOH}$ in $100 \mathrm{~mL}$ volumetric flask and sonicated for $30 \mathrm{~min}$. After hydrolysis, the solution was neutralized with sufficient volume of $0.1 \mathrm{~N} \mathrm{HCl}$ and diluted with mobile phase up to the mark.

Oxidative degradation was carried out by mixing powder equivalent of $40 \mathrm{mg}$ of esomeprazole and $150 \mathrm{mg}$ of itopride with $10 \mathrm{~mL}$ of $\mathrm{H}_{2} \mathrm{O}_{2}(3 \% \mathrm{v} / \mathrm{v})$ in a $100 \mathrm{~mL}$ volumetric flask and the resultant solution was sonicated for $30 \mathrm{~min}$. After oxidation, the solution was diluted with mobile phase up to the mark.

Photo degradation studies were carried out by the exposure of sample powder containing esomeprazole $40 \mathrm{mg}$ and itopride $150 \mathrm{mg}$ to direct sunlight for $24 \mathrm{hrs}$. The photo degraded sample was transferred to a $100 \mathrm{~mL}$ volumetric flask containing 30 $\mathrm{mL}$ of mobile phase and mixed well. The volume of the flask was completed up to mark with mobile phase.

Dry heating was performed by keeping sample powder containing esomeprazole $40 \mathrm{mg}$ and itopride $150 \mathrm{mg}$ in oven at $105^{\circ} \mathrm{C}$ for $30 \mathrm{~min}$. The treated sample was dissolved in $30 \mathrm{~mL}$ of mobile phase in a $100 \mathrm{~mL}$ volumetric flask. The contents of the flask were mixed well and diluted up to the mark with mobile phase. All forced degradation studies were analyzed at $80 \mu \mathrm{g} / \mathrm{mL}$ esomeprazole and $300 \mu \mathrm{g} / \mathrm{mL}$ itopride concentration levels.

\section{Assay of esomeprazole and itopride in bulk}

The working standard solutions, in the concentration of $40,60,80,100 \& 120 \mu \mathrm{g} / \mathrm{mL}$ esomeprazole and 150, 225, 300, $375 \& 450 \mu \mathrm{g} / \mathrm{mL}$ itopride, prepared from stock solution were injected into the column. The eluents were monitored at $272 \mathrm{~nm}$. Peak area was recorded for each concentration of drugs.

The calibration curve was plotted as concentration vs peak area. The regression equation was derived. The concentration of unknown was determined either from the calibration curve or regression equation derived.

\section{Assay of esomeprazole and itopride in combined capsule dosage forms}

Ten $\mu \mathrm{L}$ of the sample solution prepared in the section "sample solution" was injected into the HPLC system five times. The peak areas were recorded and the content of esomeprazole and itopride in combined capsule dosage form was determined from the calibration curve or from the regression equation.

\section{RESULTS AND DISCUSSION}

\section{Method development}

The main objective of the present study was to develop a stability indicating HPLC method for the simultaneous estimation of esomeprazole and itopride simultaneously in bulk and capsule dosage form and to obtain well resolved peaks of esomeprazole, itopride and their stress degradation products.

During method development, chromatographic parameters such as mobile phase composition, flow rate of mobile phase, detection wavelength, analytical column and column temperature were optimized to get improved efficiency of the chromatographic system. Two HPLC analytical columns, Phenomenex C18 (150 mm x $4.6 \mathrm{~mm} ; 5 \mu \mathrm{m}$ particle size) and Hypersil C4 (250 mm x $4.6 \mathrm{~mm} ; 5 \mu \mathrm{m}$ particle size) were tested during method development.

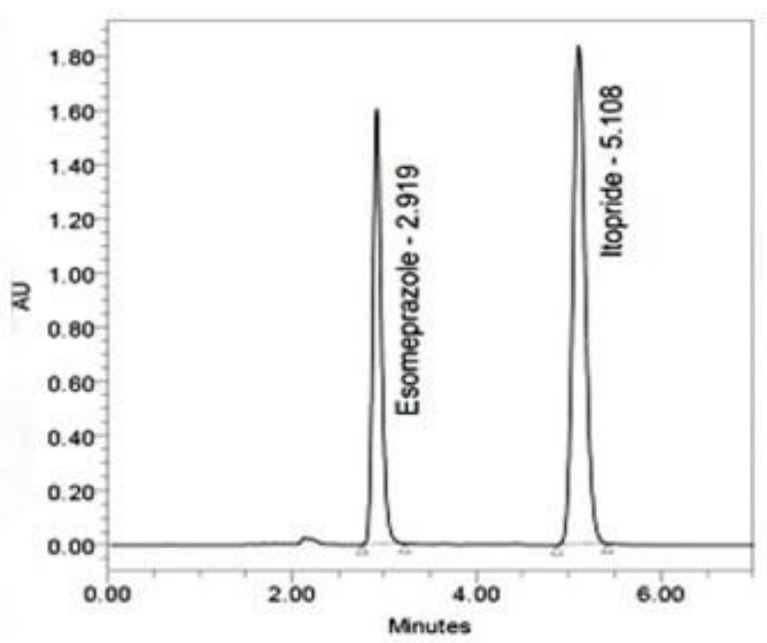

Fig. 3: Typical chromatogram of esomeprazole and itopride Method validation

The system suitability parameters like tailing factor, resolution, and plate count were considered. Based on the above said parameters Hypersil C4 column $(250 \mathrm{~mm}$ x $4.6 \mathrm{~mm} ; 5 \mu \mathrm{m}$ particle size) was finalized. Different composition of mobile phases containing a mixture $(v / v)$ of $0.1 \mathrm{M}$ dipotassium hydrogen phosphate, $0.1 \mathrm{M}$ potassium dihydrogen phosphate, $0.1 \%$ orthophosphoric acid in water and acetonitrile were evaluated so as to obtain appropriate composition of mobile phase. Finally the mixture of $0.1 \mathrm{M}$ dipotassium hydrogen phosphate and acetonitrile in the ratio of 40:60 $(v / v)$ was selected as optimal. At a flow rate of $1 \mathrm{~mL} / \mathrm{min}$ and with column temperature of $30^{\circ} \mathrm{C}$ well defined and swell resolved peaks of esomeprazole and itopride are obtained. At the wavelength $272 \mathrm{~nm}$, best detector response for 
esomeprazole and itopride was obtained. Therefore, $272 \mathrm{~nm}$ was selected as the analytical wavelength for the detection and simultaneous quantification of esomeprazole and itopride. Under the optimized chromatographic conditions, the retention time for esomeprazole and itopride was found to be $2.919 \mathrm{~min}$ and 5.108 min, respectively. The developed method was validated for system suitability, selectivity, linearity, precision, accuracy, limit of detection (LOD), limit of quantification (LOQ), specificity and robustness as per International Conference on Harmonization (ICH) guidelines (International Conference on Harmonization, 2005).

\section{System Suitability Studies}

Mixed standard solution of esomeprazole $(80 \mu \mathrm{g} / \mathrm{mL})$ and itopride $(300 \mu \mathrm{g} / \mathrm{mL})$ solution was injected in five replicates in the HPLC system to determine system suitability. System suitability parameters established for the developed method include number of relative standard deviation of peak area, theoretical plates, resolution and tailing factor. The values obtained (Table 1) demonstrated the suitability of the system for the analysis of this drug combinations.

\section{Selectivity}

The selectivity of the developed HPLC method was investigated by non-interference of excipients in capsule dosage form and components of mobile phase. Selectivity of the proposed method was demonstrated by comparing the chromatograms of standard solution of esomeprazole $(80 \mu \mathrm{g} / \mathrm{mL})$ and itopride (300 $\mu \mathrm{g} / \mathrm{mL}$ ) with the chromatogram of sample solution (containing esomeprazole $80 \mu \mathrm{g} / \mathrm{mL}$ and itopride $300 \mu \mathrm{g} / \mathrm{mL}$ ), blank mobile phase and placebo blank. The chromatograms are shown in Fig. 4. There were no difference in the chromatograms of standard solution and sample solution (Fig. 4A \& 4B). There are no peaks in the chromatogram of blank mobile phase and placebo blank (Fig. 4C \& 4D). The results indicated the selectivity of the proposed method.

Table 1: System suitability parameters.

\begin{tabular}{|c|c|c|c|}
\hline Parameters & Esomeprazole & Itopride & Recommended limits \\
\hline Retention time & $2.919(\%$ RSD -0.148$)$ & $5.108(\%$ RSD - 0.141) & - \\
\hline Peak area & $10242324(\% \mathrm{RSD}-0.109)$ & $17047280(\% \mathrm{RSD}-0.226)$ & $\mathrm{RSD} \leq 2$ \\
\hline USP resolution & - & $10.54(\%$ RSD -0.616$)$ & $>1.5$ \\
\hline USP plate count & $5008(\%$ RSD - 1.75) & 7121(\%RSD - 1.57) & $>2000$ \\
\hline USP tailing factor & $1.21(\% \mathrm{RSD}-1.012)$ & $1.13(\%$ RSD -1.083$)$ & $\leq 2$ \\
\hline
\end{tabular}
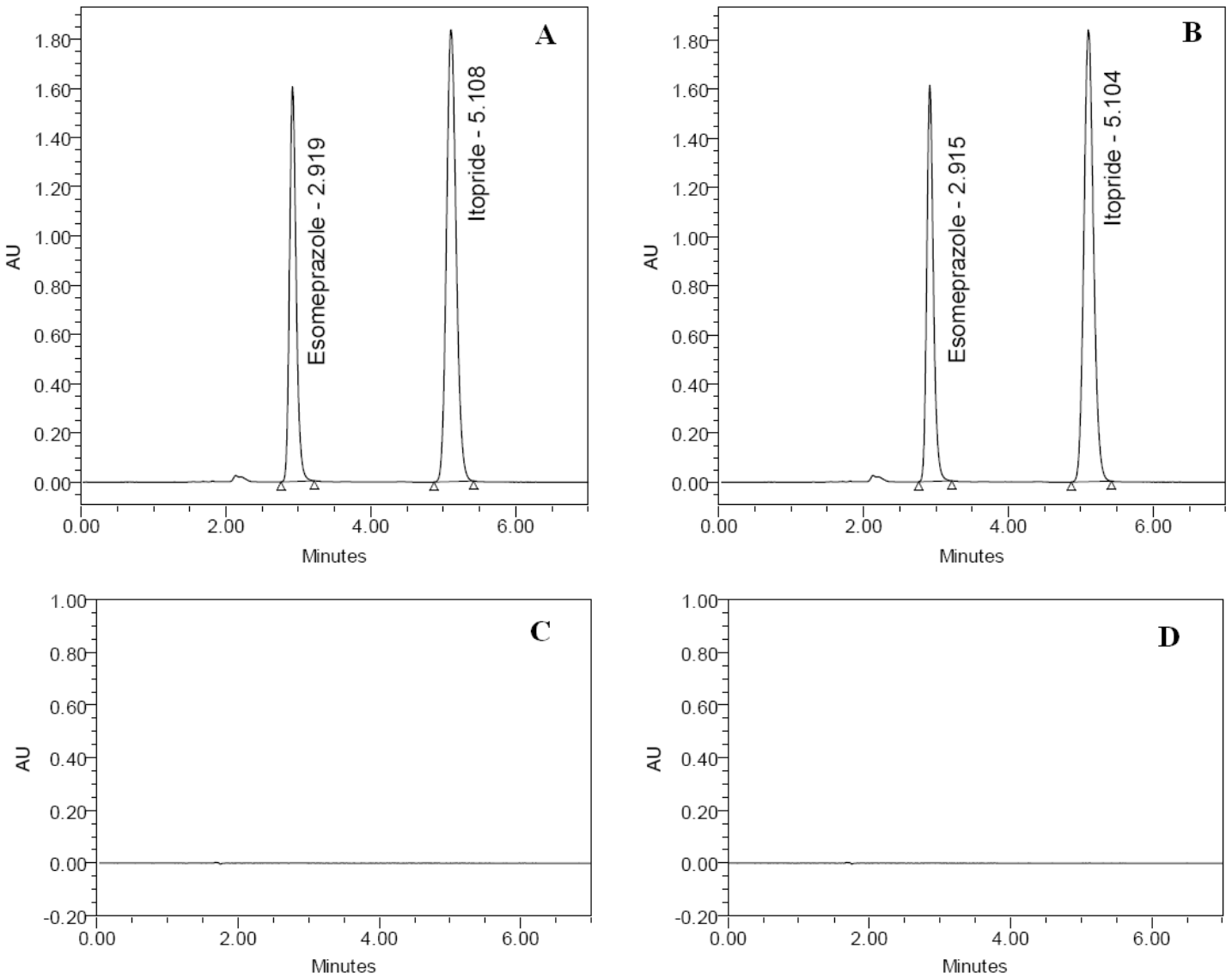

Fig. 4: Chromatogram of (A) standard drug solution (B) capsule dosage form (C) mobile phase blank (D) Placebo blank . 

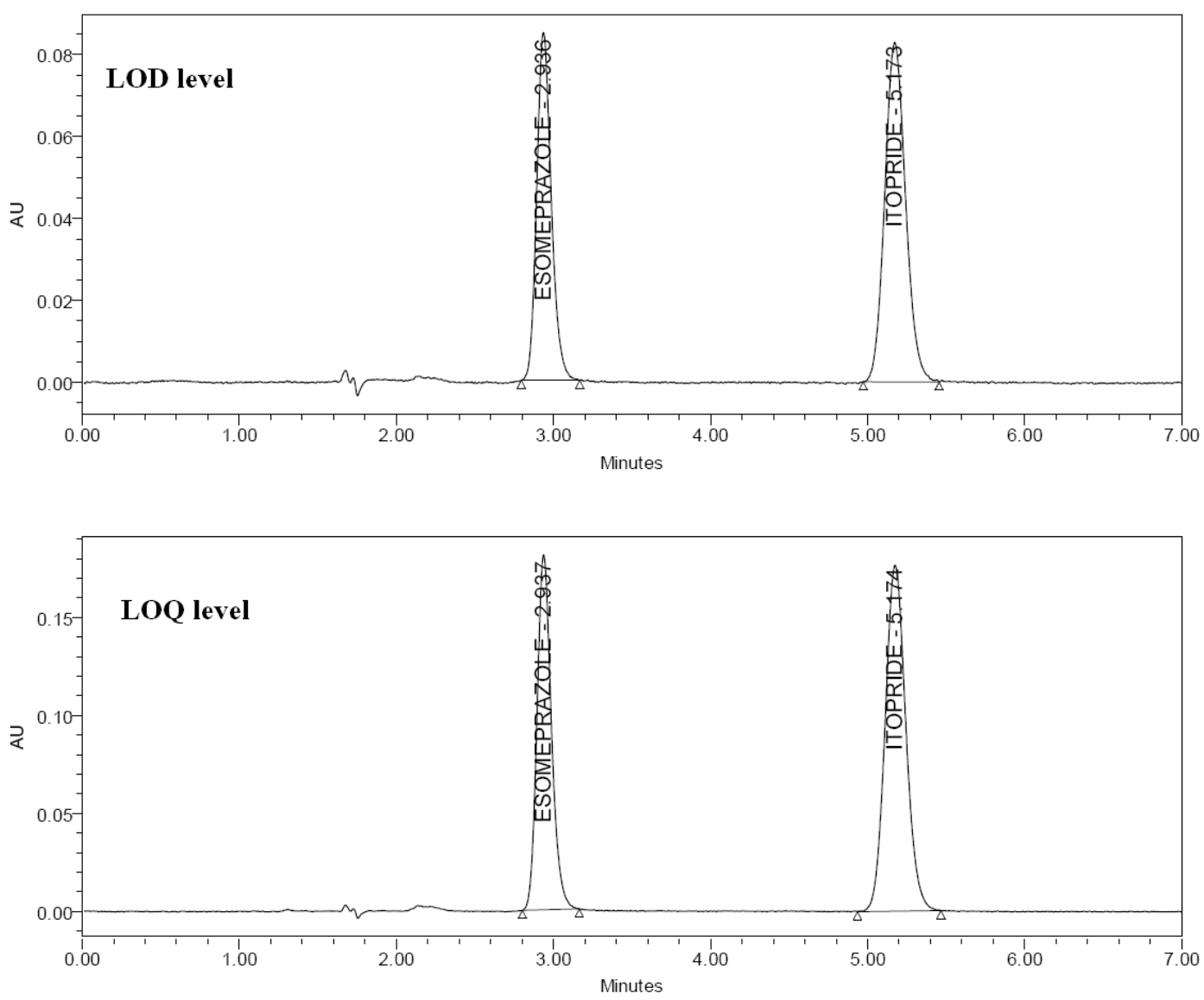

Fig. 5: Chromatograms of esomeprazole and itopride at LOD and LOQ levels.

\section{Linearity and range}

The linearity for the proposed method was established by least squares regression analysis of the calibration curve. Calibration curves were linear over the concentration range of 40$120 \mu \mathrm{g} / \mathrm{mL}$ for esomeprazole and $150-450 \mu \mathrm{g} / \mathrm{mL}$ for itopride with a regression coefficient $\left(R^{2}\right)$ of 0.9999 for both the drugs. The results shows a good correlation exists between peak area and concentration of drugs within concentration range indicated above. The results for calibration data are shown in Table 2.

Table 2: Linearity for esomeprazole and itopride by proposed method.

\begin{tabular}{cccc}
\hline \multicolumn{2}{c}{ Linearity for esomeprazole } & \multicolumn{2}{c}{ Linearity for itopride } \\
\hline $\begin{array}{c}\text { Concentration } \\
(\boldsymbol{\mu} \mathbf{g} / \mathbf{m L})\end{array}$ & Peak area & $\begin{array}{c}\text { Concentration } \\
(\boldsymbol{\mu g} / \mathbf{m L})\end{array}$ & Peak area \\
\hline 40 & 5175501 & 150 & 8576751 \\
60 & 7697342 & 225 & 12873107 \\
80 & 10305838 & 300 & 17184024 \\
100 & 12943487 & 375 & 21591549 \\
120 & 15484880 & 450 & 25907883 \\
\hline \multicolumn{2}{r}{ Regression equation: } & \multicolumn{2}{c}{$\begin{array}{c}\text { Regression equation: } \\
\mathrm{y}=129149 \mathrm{x}-8768.4\end{array}$} \\
\multicolumn{2}{c}{$\mathrm{R}^{2}=0.9999$} & \multicolumn{2}{c}{$\mathrm{R}^{2}=0.9999$} \\
\hline
\end{tabular}

\section{Limit of detection (LOD), limit of quantification (LOQ)}

The Limit of quantification and detection determines the sensitivity of the method. The LOD and LOQ were calculated using the following formulas (1) and (2).

$$
\begin{aligned}
& \text { (1) } \mathrm{LOQ}=10 \mathrm{sd} / \mathrm{S} \\
& \text { (2) } \mathrm{LOD}=3.3 \mathrm{sd} / \mathrm{S}
\end{aligned}
$$

Where, $\mathrm{sd}=$ standard deviation of response, $\mathrm{S}=$ slope of the calibration curve.

The LOD of esomeprazole and itopride was found to be 0.207 and $0.724 \mu \mathrm{g} / \mathrm{mL}$ and the LOQ of esomeprazole and itopride was 0.691 and $2.415 \mu \mathrm{g} / \mathrm{mL}$, respectively. The chromatograms of esomeprazole and itopride at LOD and LOQ levels are shown in Fig. 5. The results indicate that the developed method possess adequate sensitivity for the simultaneous determination of esomeprazole and itopride.

\section{Precision}

The precision of the proposed method was established by analyzing five standard solutions (esomeprazole- $80 \mu \mathrm{g} / \mathrm{mL}$; itopride-300 $\mu \mathrm{g} / \mathrm{mL}$ ). The peak area of esomeprazole and itopride and their percentage RSD were calculated. The results of are presented in Table 3. The results were within the acceptable limit and indicated that the method is precise. 
Table 3: Precision of the method.

\begin{tabular}{|c|c|c|c|c|c|c|}
\hline \multirow{2}{*}{ S. No. } & \multicolumn{3}{|c|}{ Esomeprazole } & \multicolumn{3}{|c|}{ Itopride } \\
\hline & Concentration $(\mu \mathrm{g} / \mathrm{mL})$ & Peak Area & $\%$ RSD & Concentration $(\mu \mathrm{g} / \mathrm{mL})$ & Peak Area & $\%$ RSD \\
\hline 1 & 80 & 10329341 & & 300 & 17027206 & \\
\hline 2 & 80 & 10375535 & & 300 & 17103866 & \\
\hline 3 & 80 & 10296899 & 0.38 & 300 & 17052015 & 0.27 \\
\hline 4 & 80 & 10288066 & & 300 & 17047562 & \\
\hline 5 & 80 & 10372197 & & 300 & 17109716 & \\
\hline
\end{tabular}

Table 4: Accuracy of the method.

\begin{tabular}{|c|c|c|c|c|}
\hline Accuracy level & $(\mu \mathrm{g} / \mathrm{mL})$ added & ( $\mu \mathrm{g} / \mathrm{mL})$ found & \% Recovery & \% Mean \\
\hline \multicolumn{5}{|c|}{ Esomeprazole } \\
\hline \multirow{3}{*}{$50 \%$} & 40.000 & 40.14 & 100.35 & \multirow{3}{*}{100.12} \\
\hline & 40.000 & 40.05 & 100.12 & \\
\hline & 40.000 & 39.96 & 99.90 & \\
\hline \multirow{3}{*}{$100 \%$} & 80.000 & 80.15 & 100.18 & \multirow{3}{*}{99.72} \\
\hline & 80.000 & 79.23 & 99.04 & \\
\hline & 80.000 & 79.96 & 99.95 & \\
\hline \multirow{3}{*}{$150 \%$} & 120.000 & 119.73 & 99.77 & \multirow{3}{*}{99.96} \\
\hline & 120.000 & 120.36 & 100.30 & \\
\hline & 120.000 & 119.80 & 99.83 & \\
\hline \multicolumn{5}{|c|}{ Itopride } \\
\hline \multirow{3}{*}{$50 \%$} & 150.000 & 150.49 & 100.33 & \multirow{3}{*}{10.10} \\
\hline & 150.000 & 149.28 & 99.52 & \\
\hline & 150.000 & 150.68 & 100.45 & \\
\hline \multirow{3}{*}{$100 \%$} & 300.000 & 300.38 & 100.12 & \multirow{3}{*}{100.03} \\
\hline & 300.000 & 298.59 & 99.53 & \\
\hline & 300.000 & 301.34 & 100.44 & \\
\hline \multirow{3}{*}{$150 \%$} & 450.000 & 450.64 & 100.14 & \multirow{3}{*}{100.01} \\
\hline & 450.000 & 448.64 & 99.69 & \\
\hline & 450.000 & 450.90 & 100.20 & \\
\hline
\end{tabular}
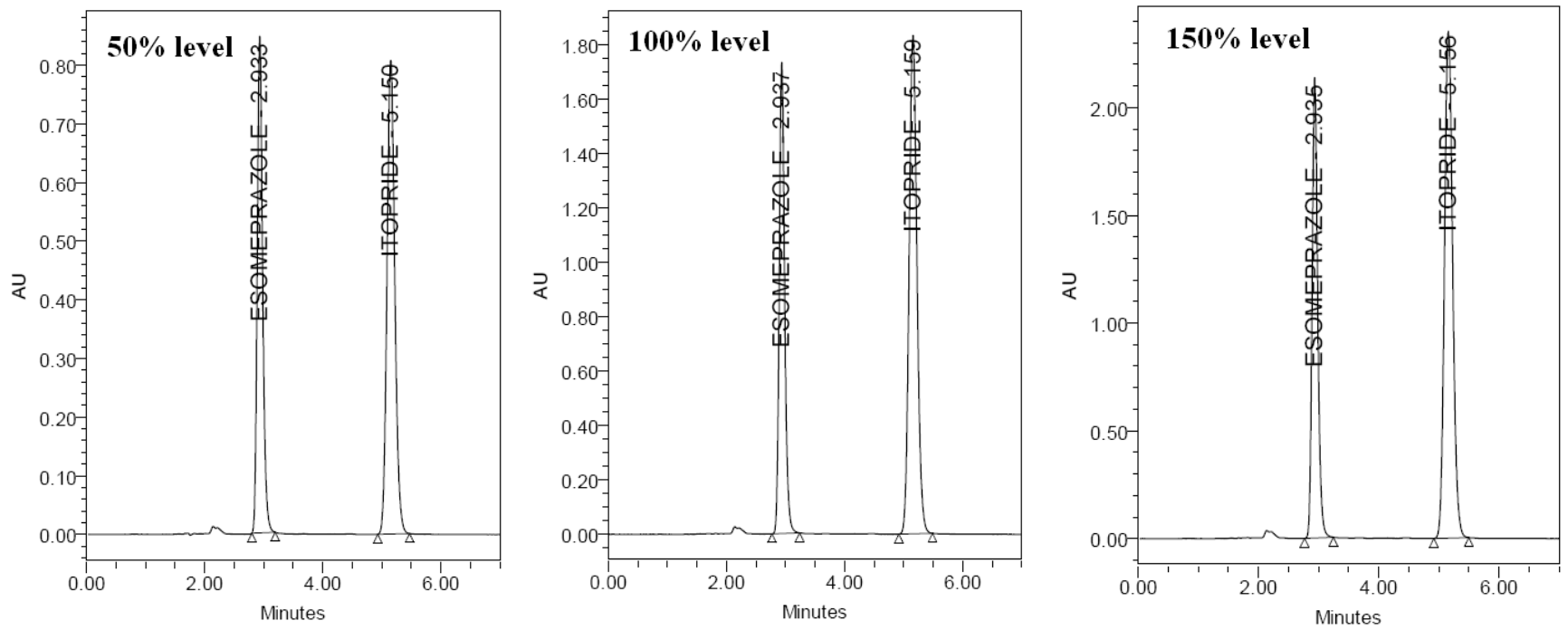

Fig. 6: Chromatograms of esomeprazole and itopride at three different levels.

\section{Accuracy}

Recovery experiments were performed to determine the accuracy of the method. The accuracy of the proposed method was established by preparing samples spiked with $50 \%, 100 \%$, and $150 \%$ of the test concentration of esomeprazole and itopride. Each concentration level was analyzed.

Mean percent recovery was calculated for each concentration. Percent recovery was well within the acceptable limit. Results are presented in Table 4. From the data, added recoveries of standard drugs were found to be accurate. The chromatograms of three different levels are shown in Fig. 6.

\section{Robustness}

The robustness test was carried out by making deliberate changes in optimized chromatographic conditions. Retention time, tailing factor, resolution and plate count were measured to demonstrate the robustness of the method. The results are shown in Table 5. In all the deliberate varied chromatographic conditions, the parameters like tailing factor, peak area and theoretical plates were not much affected, which shows that the method is robust. 
Table 5: Robustness of the method.

\begin{tabular}{|c|c|c|c|c|c|}
\hline Parameter varied & Retention time & Peak area & USP plate count & USP Tailing & USP resolution \\
\hline \multicolumn{6}{|c|}{ Esomeprazole } \\
\hline Column temperature $-29^{\circ} \mathrm{C}$ & 2.942 & 10302901 & 4998 & 1.18 & - \\
\hline Column temperature $-31^{\circ} \mathrm{C}$ & 2.944 & 10380968 & 5008 & 1.17 & - \\
\hline Flow rate $-0.9 \mathrm{~mL} / \mathrm{min}$ & 2.940 & 10352026 & 4954 & 1.19 & - \\
\hline Flow rate $-1.1 \mathrm{~mL} / \mathrm{min}$ & 2.943 & 10318635 & 5035 & 1.18 & - \\
\hline \multicolumn{6}{|c|}{ Itopride } \\
\hline Column temperature $-29^{\circ} \mathrm{C}$ & 5.183 & 17111327 & 7360 & 1.10 & 10.75 \\
\hline Column temperature $-31^{\circ} \mathrm{C}$ & 5.175 & 16952513 & 7420 & 1.14 & 10.75 \\
\hline Flow rate $-0.9 \mathrm{~mL} / \mathrm{min}$ & 5.177 & 17008673 & 7206 & 1.11 & 10.69 \\
\hline Flow rate $-1.1 \mathrm{~mL} / \mathrm{min}$ & 5.179 & 17005273 & 7262 & 1.13 & 10.71 \\
\hline
\end{tabular}

Table 6: Stress degradation studies and spectral homogeneity data.

\begin{tabular}{|c|c|c|c|c|c|c|}
\hline Type of stress & Peak area & \% Assay & \% Degradation & Purity Angle & Purity Threshold & Purity flag \\
\hline \multicolumn{7}{|c|}{ Esomeprazole } \\
\hline Undegraded & 10251788 & 100 & - & - & - & - \\
\hline Acid & 9819341 & 95 & 5 & 0.627 & 0.887 & No \\
\hline Base & 9885535 & 96 & 4 & 0.655 & 0.872 & No \\
\hline Peroxide & 9840689 & 95 & 5 & 0.643 & 0.941 & No \\
\hline Heat & 9800106 & 95 & 5 & 0.699 & 0.909 & No \\
\hline Sunlight & 9897219 & 96 & 4 & 0.616 & 0.861 & No \\
\hline \multicolumn{7}{|c|}{ Itopride } \\
\hline Undegraded & 17032285 & 100 & - & - & - & - \\
\hline Acid & 16027206 & 94 & 6 & 6.507 & 33.764 & No \\
\hline Base & 16303866 & 95 & 5 & 6.709 & 29.258 & No \\
\hline Peroxide & 16052015 & 94 & 6 & 6.786 & 33.740 & No \\
\hline Heat & 16447562 & 96 & 4 & 6.497 & 31.034 & No \\
\hline Sunlight & 16349716 & 96 & 4 & 6.959 & 33.546 & No \\
\hline
\end{tabular}
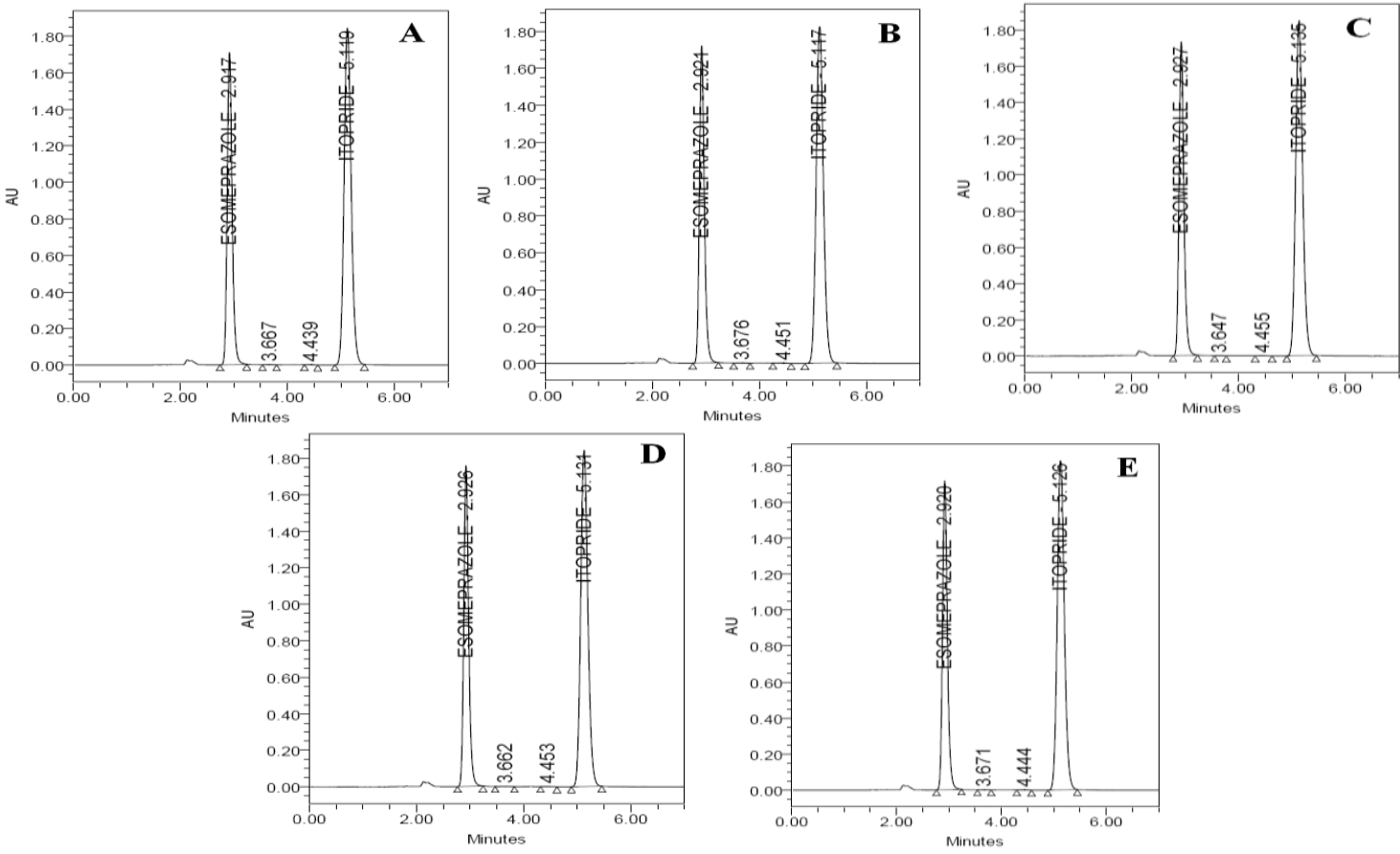

Fig. 7: Chromatograms of esomeprazole and itopride after stress degradation (A) Acid (B) Base (C) Hydrogen peroxide (D) Dry heat (E) Photolytic.

\section{Stress degradation study}

The stress degradation study was done to make sure that the proposed method was able to separate esomeprazole and itopride from the degradation products generated during the stress degradation study. The results of degradation study are summarized in Table 6. The chromatograms of degraded samples are shown in Fig. 7. The degradation products produced due to stress did not interfere with the detection of esomeprazole and itopride, and the proposed method can thus be regarded as stability-indicating.

For all stress degradation samples, the purity angle was less than the threshold angle and there was no purity flag for esomeprazole and itopride. The confirmation of peak purity indicates that there is no interference from stress degradants, facilitating quantification of esomeprazole and itopride without error. 


\section{CONCLUSION}

The proposed stability indicating HPLC method was found to be rapid, simple, precise, accurate, selective and sensitive for the simultaneous estimation of esomeprazole and itopride in capsules. Therefore, this method can easily and conveniently take up for routine quality control analysis of esomeprazole and itopride in bulk and in capsules.

\section{ACKNOWLEDGEMENT}

Authors are thankful to Acharya Nagarjuna University, Nagarjuna nagar, Guntur for support and encouragement.

\section{REFERENCES}

Akheel AS, Ayesha S. Neocuproine and bathocuproine as new reagents for the spectrophotometric determination of certain proton pump inhibitors. Chem Soc Ethiopia, 2007; 21: 315-321.

Bellah SMd, Motalib MMdA, Mostaharul IMd, Khan MdS, Anisuzzaman SMd. Development and validation of method for determination of esomeprazole by HPLC. Int Res J Pharm, 2012; 3: 227 232.

Choudhary B, Goyal A, Khokra SL, Kaushik D. New visible spectrophotometric method for estimation of itopride hydrochloride from tablets formulations using methyl orange reagent. Int J Pharm Pharm Sci, 2009A; 1: 159-162.

Choudhary B, Goyal A, Khokra SL, Kaushik D. New visible spectrophotometric method for estimation of Itopride hydrochloride from tablets using mordant blue 3 reagent. Oriental J Chem, 2009B; 25: 779781

Dighe VV. High-performance thin-layer chromatographic determination of itopride hydrochloride in its pharmaceutical preparation and in the bulk drug. J Planar Chromatogr-Mod. TLC, 2007; 19: 319-323.

Evangelos K, Einar B. A review of esomeprazole in the treatment of gastroesophageal reflux disease (GERD). Ther Clin Risk Manag, 2007; 3: 653-663.

Felice CS, Saradhi SV. Determination and validation of visible spectrophotometric method for itopride in dosage forms. Int J Sys Tech, 2008; 1 : 39-43.

Gupta KR, R Joshi RR, Chawla RB, Wadodkar SG. UV Spectrophotometric method for the estimation of itopride hydrochloride in pharmaceutical formulation. E-J Chem, 2010; 7: S49-S54.

Heon WL. Ji-Hyung S, Seung-Ki C, Kyung-Tae L. Determination of itopride in human plasma by liquid chromatography coupled to tandem mass spectrometric detection: Application to a bioequivalence study. Anal Chim Acta, 2007; 583: 118-123.

Huang X, Lv B, Zhang S, Fan YH, Meng LN. Itopride therapy for functional dyspepsia: a meta-analysis. World J Gastroenterol, 2012; 18: 7371-7377.

Hussainy AS, Smitha G, Swamy PV, Raju SA. Spectrophotometric determination of itopride hydrochloride. Int J Chem Sci, 2006; 4: 713-716.

Hultman I., Stenhoff H., Liljeblad M. Determination of esomeprazole and its two main metabolites in human, rat and dog plasma by liquid chromatography with tandem mass spectrometry. J Chromatogr B Analyt Technol Biomed Life Sci, 2007; 848: 317

International Conference on Harmonization, Validation of Analytical Procedure, Text and Methodology Q2 (R1), IFMA, Geneva, Switzerland, 2005

Kaul N, Agrawal H, Maske, PR, Ramchandra J, Mahadik, KR, Kadam, SS. Chromatographic determination of itopride hydrochloride in the presence of its degradation products. J Separ Sci, 2005; 28: 1566-1576.

Khalil MdT, Usman Md, Khan GM, Awan SB, Bibi H, Siddiqua A. HPLC method development and validation for the estimation of esomeprazole in bulk and pharmaceutical dosage form. Int J Drug Dev \& Res, 2012; 4: 252-256.

Khalil S. Micro-determination of itopride hydrochloride in pharmaceutical formulations and urine samples using icp-atomic emission spectrometry. Int J Pharm Bio Sci, 2013; 4: 786-794

Kumar SA, Harish A, Debnath M, Krishna NS, Saravanan J, Greeshma V, Rao CNM. A new, simple and accurate method development and validation for simultaneous estimation of esomeprazole and itopride in pharmaceutical dosage form by using RP -HPLC. Res J Pharm Techn, 2014; 7: 221-228

Ma J, Yuan LH, Ding MJ, Zhang J, Zhang Q, Xu QW, Zhou XM. Determination of itopride hydrochloride in human plasma by RP HPLC with fluorescence detection and its use in bioequivalence study. Pharmacol Res, 2009; 59:189-193.

Magesh AR, Vijayalakshmi R, Satyavati D, Sravanthi Devi G, Dhanaraju MD. Validated spectrophotometric estimation of esomeprazole using hydrotrophic solubilisation technique. Oriental J Chem, 2010; 26: 1191-1193.

Mahaparale SP, Deshpande SV. Analytical method development of esomeprazole in tablet dosage form by RP-HPLC method. Int J Pharma Chem Res, 2015; 4: 1-5.

McKeage K, Blick SK, Croxtall JD, Lyseng-Williamson KA, Keating GM. Esomeprazole: a review of its use in the management of gastric acid-related diseases in adults. Drugs, 2008; 68: 1571-1607.

Mohamed IW, Fawzia I, Manal IE, Samah AE. StabilityIndicating spectrofluorimetric method for determination of itopride hydrochloride in raw material and pharmaceutical formulations. J Fluores, 2013; 23 : 1293-1300.

Nafisur R, Zehra B, Syed NHA. Spectrophotometric Determination of esomeprazole magnesium using 5-sulfosalicylic acid and N-bromosuccinimide. J Chinese Chem Soc, 2008; 55: 557-566.

Nalwade SU, Reddy VR, Rao DD, Morisetti NK. A validated stability indicating ultra performance liquid chromatographic method for determination of impurities in esomeprazole magnesium gastro resistant tablets. J Pharm Biomed, 2012; 57: 109-114.

Neeraj K, Himani A, Pravin M, Janhavi RR, Kakasaheb RM, Shivajirao SK. Chromatographic determination of itopride hydrochloride in the presence of its degradation products. J Separ Sci, 2005; 28: 15661576

ÖNal A, ÖZtunÇ A. Development and validation of high performance liquid chromatographic method for the determination of esomeprazole in tablets. J Food Drug Anal, 2006; 14: 12-18.

Patil SS, Dhabale PN, Kuchekar BS, Development and Statistical Validation of Spectrophotometric method for estimation of esomeprazole in tablet dosage form, Asian J Res Chem, 2009; 2: 154-156.

Pavel P, Josef K, Jan M. Optimized method for the determination of itopride in human plasma by high-performance liquid chromatography with flourometric detection. J Chromatogr B, 2009; 877: 842-846.

Payal J, Suvarna B, Bhagwat AM, Vishwanath K, Jadhav RK. Identification of forced degradation products of itopride by LC-PDA and LC-MS. Indian J Pharm Sci, 2011; 73: 287-291.

Peng JC, Li YZ. Itopride esomeprazole treatment of the value of non-erosive gastroesophageal reflux disease. 2009 http://www.yourpaper.net/article/20091208/228535.

Putta RK, Somashekar S, Mallikarjuna GM, Shanta SMK. Physico-chemical characterization, UV spectrophotometric method development and validation studies of esomeprazole magnesium trihydrate. J Chem Pharm Res, 2010; 2: 484-490.

Rajesh KP, Bhuvan PR, Bhavesh HP, Laxman JP. Reverse phase high performance liquid chromatographic method for the simultaneous estimation of esomeprazole and itopride in capsule. Der Pharma Chemica, 2010; 2: 251-260.

Ramakotaiah M, Kanchanamala K, Chandrasekhar KB, Babu Rao C, Bala sekhara reddy C. Quantification of esomeprazole in human plasma by liquid chromatography tandem mass spectrometry and its application to bioequivalence study. Der Pharmacia Lettre, 2011; 3: 138 145 . 
Santosh UZ, Paresh IK, Jitendra WG. Spectrophotometric method development and validation of itopride hydrochloride in bulk and dosage form. Int J Drug Deliv, 2010; 2: 340-343.

Sathiyaraj M, Amirtharaj RV, Senthilkumar N. Bioanalytical Method Development and validation of esomepraole in human plasma by LCMS/MS. Asian J Res Chem, 2010; 3: 477- 484.

Shetty R, Subramanian G, Kumar RA, Pandey S, Udupa N. Estimation of esomeprazole in human plasma by reverse phase high performance liquid chromatography. Indian Drugs, 2005; 42: 158-161.

Singh SS, Jain M, Sharma K, Shah B, Vyas M, Thakpar P, Quantitation of itopride in human serum by high performance liquid chromatography with fluorescence detection and its application to a bioequivalence study. J Charatogr B Analyst Technol Biomed Life Sci, 2005; 818: 213-220.

Sneha GN, Jaivik VS, Priyanka AS, Mallika S, Pranav SS. Spectrophotometric determination of five commercial drugs in pure form and pharmaceutical formulations by ion-pair complexation with alizarin red S. Eurasian J Anal Chem 2015; 10: 68-83.

Soujanya P, Ramakrishna Ch, Parveen SN, Vyshnavi R, Vijaya SS. Standardization of analytical procedures for the estimation of esomerprazole in bulk and dosage forms. J Appl BioSci Res, 2014; 1: 16 19.

Suganthi A, Karthikeyan R, Ravi TK. HPTLC methods for estimation of Itopride hydrochloride from its tablet formulations. Indian Drugs, 2006; 43: 827-830.

Sun J, Yuan YZ, Holtmann G. Itopride in the treatment of functional dyspepsia in Chinese patients: a prospective, multicentre, postmarketing observational study. Clin Drug Investig, 2011; 31: 865-875.
Thiruvengada RV, Mohamed ST, Ramkanth S, Alagusundaram M, Ganaprakash K and Madhusudhana CC. A simple RP-HPLC method for quantitation of itopride $\mathrm{HCl}$ in tablet dosage form. J Young Pharm, 2010; 2 : 410-413.

Vidya VD, Ramesh TS, Shashikumar NM, Harsha NT, Sreedevi P. Determination of Itopride Hydrochloride in its pharmaceutical preparation and in bulk drug. J Planar Chromatogr-Mod TLC, 2006; 19: 319-323

Wang M, Chen J. The clinical detection of curing reflux esophagitis by esomeprazole and itopride. Guide of China Medicine, 2012-12

Zhao Y. Hubei Provincial Institute for Drug Control, Wuhan 430064. Determination of Itopride Hydrochloride in capsule formulation by HPLC. Tianjin pharmacy, 2000-2002

\section{How to cite this article:}

Rao MN, Krishna KBM and HariBabu B. Development and Validation of A Stability Indicating HPLC Method for the Simultaneous Analysis of Esomeprazole and Itopride in Bulk and In Capsules. J App Pharm Sci, 2016; 6 (02): 072-080. 